\title{
A NOVA LDB E A
}

\section{FORMAÇÃO DE PROFISSIONAIS PARA A INTER-RELAÇÃO COMUNICAÇÃO/ EDUCAÇÃO}

Em maio de 1992, a Câmara do Deputados aprovou o texto da nova LDB - Lei de Diretrizes e Bases de Educação Nacional. O artigo 36 do Projeto estabelece a obrigatoriedade da introdução de Leitura Crítica da Comunicação como parte do currículo. Já em setembro de 1994, o Conselho Federal de Educação aprovou a instalação do primeiro Curso de Comunicação Educacional, solicitado por uma Faculdade de Comunicação Social em São Paulo. São acontecimentos que colocam na linha do debate nacional o campo da formação de profissionais para a inter-relação Comunicação/Educação.

O texto do novo Projeto da Lei de Diretrizes e Bases da Educação Nacional, recém-aprovado pela Câmara dos Deputados e que se encontra em tramitação no Senado da República, veio ao encontro das aspirações de muitos docentes e pesquisadores preocupados em modernizar o ensino sem abdicar de uma filosofia de educação voltada essencialmente para a formação do cidadão cultural e politicamente ativo.

A LDB estabelece que o sistema nacional de educação terá como um de seus fins "a formação de cidadãos capazes de compreender criticamente a realidade social" (art. $2^{\circ}$, II) e que tenham desenvolvida sua capacidade de reflexão e criação (art. 44, II e 47, III) para o que, na intenção do legislador, certamente contribuirá o "desenvolvi- mento de critérios de leitura crítica dos meios de comunicação social" (art. 36, V).

A nova exigência legal cria um desafio para os que se propõem edificar uma educação com qualidade.

O artigo 36 da Lei de Diretrizes e Bases da Educação Nacional não só introduz nos conteúdos curriculares da educação básica

\section{O AUTOR}

Ismar de Oliveira Soares

Professor do Departamento de Comunicações e Artes da ECA-USP (Escola de Comunicações e Artes da Universidade de São Paulo) e fundador do Programa Latino-Americano de Formação Superior em Planejamento e Avaliação de Processos Comunicacionais. 
(educação infantil, ensino fundamental e ensino médio) o desenvolvimento de critérios de leitura crítica dos meios de comunicação social, como também prevê uma efetiva iniciação tecnológica no campo da comunicação.

O que tais mudanças poderão significar para um projeto de maximização da qualidade do ensino superior, na passagem para o terceiro milênio?

Certamente que a ampliação e a diversificação do campo de trabalho dos Institutos e Escolas de Educação e de Comunicação, quando não uma atuação integrada dessas duas áreas em atividades multidisciplinares.

\section{A NOVA LDB E A EDUCAÇÃO PARA A COMUNICAÇÃO}

O tema da qualidade do ensino está, para alguns, intimamente associado à administração dos recursos educativos, tanto materiais quanto humanos (educação de qualidade é aquela que maximiza o emprego dos investimentos humanos e econômicos). Para outros, há uma visão quantitativa dos processos de ensino/aprendizagem (educação de qualidade é aquela que pode ser mensurada em seus resultados imediatos, a partir do cumprimento de metas facilmente aferíveis). Na mesma linha de pensamento, há, ainda, os que identificam qualidade de ensino com o emprego de tecnologias de ponta, tomando como padrões modelos implementados em escolas reconhecidas no mercado como de excelente qualidade, ainda que inadequados e inacessíveis para a maioria dos estabelecimentos de ensino.

Perspectivas legítimas, segundo as filosofias que as sustentam, mas insuficientes para atender ao que solicita a nova LDB.

Inicialmente, devemos lembrar a origem social do Projeto aprovado pelos De- putados. Sua gestação durou cinco anos, tendo sido desenhado a partir de 1988, momento em que o Congresso Nacional promulgava a nova Constituição. Para o texto final, contribuíram dezenas de entidades representativas da sociedade civil. Apesar dos reparos que as diferentes filosofias de educação democraticamente implantadas em nosso meio possam lhe fazer, a nova LDB representa e manifesta, de certa forma, a vontade nacional. E o que a opinião média dos educadores brasileiros estabelece como meta para a educação nacional? Que ela, sobretudo,

forme cidadãos com capacidade de discernimento, com critérios, em condições de fazer a leitura do mundo e, em decorrência, que forme cidadãos capazes de intervir socialmente,

a partir, naturalmente, dos instrumentos que a própria sociedade colocar à disposição de cada um; instrumentos para cujo uso e manuseio a escola, segundo sua especificidade, deverá contribuir plenamente.

Nesse sentido, a nova Lei volta-se, no artigo 36, para o campo das tecnologias, incluindo-as tanto como conteúdo curricular quanto como recurso didático, do que se deduz a introdução do computador, do rádio, do vídeo e de outros engenhos modernos como objetos da aprendizagem e não apenas como linguagem ou recurso didático.

Os alunos terão, assim, direito de saber sobre a informática, sobre o rádio, sobre a televisão, sobre o jornal.

Nesse sentido, a Lei introduz, no Brasil, uma prática pedagógica que já vem se tornando costume consagrado nos países do Primeiro Mundo. 


\section{OS MEIOS DE COMUNICAÇÃO NO ENSINO}

A nova Lei entende que os primeiros a serem iniciados no uso das tecnologias sejam os professores que desempenham atividades junto às crianças da educação fundamental, determinando que a "modalidade normal" do ensino médio inclua em seu currículo o estudo dos recursos que facilitem os processos de comunicação na educação (art. 49 , parágrafo $3^{\circ}$ ).

Ainda que tenha reduzido, em seu $\mathrm{ca}$ put, o âmbito disciplinar de seus artigos apenas à educação escolar (art. $1^{\circ}$, parágrafo $\left.1^{\circ}\right)$, o Projeto garante espaço para o emprego das modernas tecnologias na educação não-formal. Exige, por exemplo, tratamento diferenciado à educação a distância por parte dos correios, telégrafos, emissoras de rádio e de televisão. Prevê a concessão de canais com finalidades exclusivamente educativas e a reserva de tempo mínimo, sem ônus para o Poder Público, pelos concessionários de canais comerciais (art. 86, I a IV). A educação a distância é assegurada especialmente na implementação de programas de aperfeiçoamento de professores (art. 88, parágrafo $3^{\circ}$ ).

O artigo 119 (II, a) dá o prazo de 180 dias depois da promulgação da Lei para que o Poder Executivo submeta ao Congresso Nacional projeto de lei reservando horários nos canais comerciais de radiodifusão para programas públicos de educação, definindo os canais que ficarão reservados exclusivamente para este fim e estabelecendo a redução das tarifas e outros custos para a educação a distância.

A Lei não especifica a quem caberá a administração dessa modalidade de educação, deixando aberto o uso do espaço tecnológico para a realização de experiências por parte tanto da iniciativa pública quanto da particular.

Por outro lado, a lei garante "a disponibilidade de aparelhagens e demais condições para recepção de programas de teleducação no local de trabalho, em empresas e órgãos públicos com mais de cem empregados" (art. 56, parágrafo $1^{\circ}$ ). Em decorrência, caberá aos Departamentos de Recursos Humanos de tais empresas e órgãos públicos dar tratamento profissional a esta exigência.

Há vinte anos que a Lei em vigor admite o ensino da comunicação na modalidade da educação profissionalizante. Proliferaram, assim, no início dos anos 70 , cursos profissionalizantes de $2^{\circ}$ grau voltados para o campo da comunicação, principalmente na área de publicidade e propaganda.

A nova LDB não desconhece essa possibilidade. Abre espaço, contudo, para que os recursos da comunicação possam também ser estudados, analisados e manipulados como conteúdos programáticos.

Uma vez que isto existe na lei e, na prática, só é realidade em uns poucos estabelecimentos de ensino, caberá aos interessados no tema trabalhar para que o Sistema Nacional de Ensino preveja modalidades de introdução da Comunicação Social no ensino formal, em todos os níveis.

\section{LEITURA CRÍTICA DA COMUNICAÇÃO: EXPERIÊNCIAS DA EDUCAÇÃO NÃO-FORMAL}

$O$ reconhecimento oficial de que o ensino básico deve se preocupar com as mensagens produzidas pela indústria cultural é um dos principais avanços da nova LDB. 
Na verdade, trata-se de um dispositivo já adotado pela prática educativa de países como os Estados Unidos, a França, a Suíça, a Inglaterra, a Austrália, o Chile, entre tantos outros. Na América Latina, o tema vem sendo campo de trabalho experimental de numerosas organizações não-governamentais dedicadas especialmente à educação popular.

Em recente pesquisa junto aos programas voltados para a análise crítica das mensagens dos meios de comunicação, desenvolvidos sistematicamente, na América Latina, desde 1970, por instituições dedicadas à educação não-formal ou mesmo à educação escolar,

pudemos identificar três grandes eixos geradores de conteúdos e de metodologias de trabalho junto a grupos de estudantes: as vertentes "moralista", "culturalista" e "dialético-indutiva".

A vertente "moralista" justifica-se pelo receio da perversão moral causada pelo alto grau de violência dos programas e por sua inadequação aos padrões morais estabelecidos como justos pelo grupo social ao qual pertence, e, principalmente, pelas religiões, que oferecem as medidas do aceitável. Trata-se de um projeto educativo que procura coibir o uso dos meios massivos, apelando, se necessário, para a censura do Estado sobre os veículos e os produtores culturais.

Um segundo núcleo de programas educativos pode ser denominado como "culturalista", por tomar como justificativa para a inclusão do estudo da comunicação nos sistemas de ensino a importância decisiva dos veículos de comunicação para a formação da opinião pública. A vertente culturalista foi possibilitada pelo desenvolvimento das Ciências Sociais, apropriadas pelo campo da Comunicação, principalmente a Psicologia, a Sociologia, a Antropologia e a Semiologia. Os sistemas de ensino que adotam esta vertente chegam a introduzir no currículo disciplinas especialmente voltadas para a análise das mensagens e das linguagens dos meios massivos, especialmente da televisão. Enquanto acreditam no poder persuasivo das mensagens, têm também como certo que basta ressemantizar os conteúdos das mensagens para vacinar os receptores quanto aos seus possíveis impactos maléficos.

Os programas de educação para a comunicação que seguem um eixo "dialético-indutivo" não apenas tomam como referencial os aspectos "culturais" ou mesmo "morais" das mensagens, como também fazem da própria relação dos indivíduos com o sistema de meios seu objeto de preocupação.

Têm como campo de leitura tanto a produção dos veículos de comunicação quanto a própria produção cultural de grupo de educandos. Estão voltados para a indústria cultural, assim como para a apropriação das linguagens dos meios de comunicação por parte dos educandos para o exercício da cidadania.

Se tais programas de ensino são dialéticos, porque estabelecem o confronto, por conseguinte são indutivos, porque partem da metodologia do "aprender-fazendo".

Os vinte anos de experiência no campo da leitura crítica da comunicação começam a ser divulgados, analisados e a servir de paradigmas para novas iniciativas. Seus resultados positivos certamente contribuíram para que o legislador se sentisse motivado a introduzir o assunto no sistema formal de ensino, em todo o país. 


\section{O ENSINO SUPERIOR E A INTRODUÇÃO DA COMUNICAÇÃO SOCIAL NA EDUCAÇÃO}

Não há dúvida de que cabe ao ensino superior, principalmente em suas áreas de pesquisa e extensão, tomar conhecimento dessas práticas e observar o que delas pode ser aproveitado e socializado no momento em que as normas estabelecidas pela LDB tiverem de ser levadas à prática.

As bibliografias correntes, quer no campo da comunicação quer no da educação, vêm dando conta, ultimamente, do alto grau de interação entre os dois universos do saber humano. Predomina, contudo, nas políticas de ensino, uma verdadeira dicotomia que mantém isolados, em universos estanques, o mundo da Comunicação e o mundo da Educação. Uma dicotomia que se manifesta introjetada principalmente nos processos de formação dos profissionais de uma ou outra área.

Aproximidamente 360 Faculdades de Educação ignoram, comumente, a problemática representada pela presença dos meios de comunicação na sociedade

e pouca contribuição prática ofereceram aos programas de educação para a comunicação ou de "leitura crítica dos meios", implantados no país nos últimos vinte anos. Até mesmo a disciplina "Tecnologia Educacional" vem perdendo espaço nos currículos das Licenciaturas.

Já as 75 Faculdades de Comunicação estão voltadas para as demandas do mercado constituído pelos meios (jornal, rádio, televisão) e pelos processos empresariais de comunicação (relações públicas, publicidade e propaganda, entre outros), desconsiderando, em sua grande maioria, as possibilidades de contribuir, de alguma forma, para a preparação de profissionais para os processos educacionais.

Diante desta constatação, cabe-nos perguntar: Como dar cobertura à nova demanda social revelada pelas exigências decorrentes da implantação da nova LDB no campo da formação profissional, tanto na área da introdução das tecnologias no ensino quanto na da educação crítica? $\mathrm{Ou}$, ainda, como preparar profissionais em condições de tratar simultaneamente a comunicação como mediação cultural e como recurso tecnológico nos processos de ensino/ aprendizagem? $\mathrm{O}$ assunto, na verdade, não interessa apenas aos brasileiros. Ainda no início do presente ano, a FELAFACS - Federación Latinoamericana de Facultades de Comunicación - constituiu um Grupo de Trabalho formado por docentes e pesquisadores do Peru (Teresa Quiroz), México (Guilherme Orozco), Brasil (Ismar de Oliveira Soares) e Colômbia (Gabriel Jaime Perez) para iniciar o debate no âmbito continental.

Acreditamos na necessidade de programas integrados, envolvendo especialistas dos dois campos do saber.

Poderíamos pensar, por exemplo, numa proposta que incluísse, em sua fase inicial, a oferta de Cursos de Especialização pelas Faculdades de Comunicação Social, desenhados a partir de conteúdos programáticos oriundos de núcleos temáticos que tomem em conta interesses das duas áreas. Trata-se de uma proposta interdisciplinar a ser endereçada a comunicadores e educadores em serviço que manifestem especial vocação para o campo comunicacional. A iniciativa certamente teria mais possibilidade de sucesso numa Universidade que mantenha, 
ao lado da Faculdade de Comunicação, um Instituto ou Faculdade de Educação.

Nesse campo, o Departamento de Comunicações e Artes da ECA-USP tomou a iniciativa de iniciar o Curso de Pós-Graduação lato sensu Gestão de Processos Comunicacionais, em que se insere um campo específico para os estudos da interrelação Comunicação/Educação. Um dos resultados deste campo é a revista Comunicação e Educação. A Universidade Javeriana de Bogotá, Colômbia, introduziu recentemente o curso de Gestão de Processos Comunicacionais, em nível de mestrado, com ênfase em Comunicação e Educação, assim como o fará, em breve, a Universidade Ibero-Americana do México e a Universidade Católica do Equador.

Outra proposta é a de iniciar um debate nacional em torno da criação de Bacharelados de Comunicação e Educação.

A proposta ganha relevância frente ao fato de o Conselho Federal de Educação ter aprovado, em setembro de 1994 , a criação do Curso de Comunicação Educacional, solicitado pela Faculdade de Comunicação Anhembi-Morumbi. Acresça-se o fato de que o Fórum das Licenciaturas, promovido pela Universidade de São Paulo, entre 1992 e 1993, concluiu pela necessidade e urgência de se estruturar uma Licenciatura em Comunicação Social.

Além do proposto, a nova LDB está exigindo a implementação de atividades de reciclagem de docentes em serviço, nos moldes do Curso de Leitura Crítica da Comunicação, oferecido pela UCBC União Cristã Brasileira de Comunicações, desde 1980. Foi, na verdade, graças ao esforço da UCBC que o tema da educação do senso crítico frente aos processos comunicativos alcançou legitimidade acadêmica e possibilitou a consolidação de metodologias aplicáveis no dia-a-dia do trabalho pedagógico.

O desafio está lançado. Estamos colhendo subsídios para manter e ampliar esta discussão. 